\title{
Safe standard remnant liver volume after hepatectomy in HCC patients in different stages of hepatic fibrosis
}

\author{
Zhiming Zhang ${ }^{1 \dagger}$, Gaoxiong Ouyang ${ }^{1 \dagger}$, Peng Wang ${ }^{2}$, Yuan Ren', Yukai Liu' ${ }^{1}$ Jun Chen ${ }^{3}$, Yumei Zhang ${ }^{4}$, \\ Jianyong Liu ${ }^{1}$ and Lequn $\mathrm{Li}^{1^{*}}$ (D)
}

\begin{abstract}
Background: To determine the standard remnant liver volume (SRLV) threshold to avoid postoperative hepatic insufficiency inpatients in different stages of hepatic fibrosis who undergo right hemi-hepatectomy.

Methods: Data for 85 patients at our single medical center were analysed prospectively to examine whether the following factors differed significantly between those who experienced postoperative hepatic insufficiency and those who did not: height, prothrombin time, remnant liver volume, SRLV or hepatic fibrosis stage.

Results: Logistic regression showed SRLV and hepatic fibrosis stage to be independent risk factors for postoperative hepatic insufficiency. The threshold SRLV for predicting insufficiency was $203.2 \mathrm{ml} / \mathrm{m}^{2}$ across all patients [area under receiver operating characteristic curve (AUC) 0.778 , sensitivity $66.67 \%$, specificity $83.64 \%, p<0.0001), 193.8 \mathrm{ml} / \mathrm{m}^{2}$ for patients with severe hepatic fibrosis (AUC 0.938, sensitivity 91.30\%, specificity $85.71 \%, p<0.0001$ ), and $224.3 \mathrm{ml} / \mathrm{m}^{2}$ for patients with cirrhosis (AUC 0.888, sensitivity 100\%, specificity 64.29\%, $\mathrm{p}<0.0001$ ).
\end{abstract}

Conclusions: Right hemi-hepatectomy may be safer in Chinese patients when the standard remnant liver volume is more than $203.2 \mathrm{ml} / \mathrm{m}^{2}$ in the absence of hepatic fibrosis or cirrhosis, $193.8 \mathrm{ml} / \mathrm{m}^{2}$ in the presence of severe hepatic fibrosis or $224.3 \mathrm{ml} / \mathrm{m}^{2}$ in the presence of cirrhosis.

Keywords: Standard remnant liver volume, Hepatectomy, HCC, Hepatic fibrosis, Cirrhosis

\section{Background}

Hepatocellular carcinoma ( $\mathrm{HCC})$ is the third leading cause of cancer-related mortality and accounts for one-fifth of all cancer cases worldwide [1]. Numerous treatments are in use, including surgical resection, transcatheter arterial chemoembolisation, radiofrequency ablation, radiotherapy, chemotherapy, and immunotherapy $[2,3]$. Liver resection remains the best treatment

\footnotetext{
*Correspondence: lequn_li12@163.com

†Zhiming Zhang and Gaoxiong Ouyang contributed equally to this work

1 Department of Hepatobiliary Surgery, Guangxi Medical University

Cancer Hospital, No. 71 Hedi Road, Nanning 530021, Guangxi Zhuang

Autonomous Region, China

Full list of author information is available at the end of the article
}

for HCC patients who cannot undergo liver transplantation [4]. However, sufficient remnant liver volume must be retained to meet the demands of metabolism and maintain homeostasis. Otherwise, the patient may suffer impaired liver function, liver failure and death $[5,6]$. Therefore, it is particularly important to determine how much remnant liver volume should be retained after hepatectomy in each patient.

Standard remnant liver volume (SRLV), in which remnant liver volume is measured using multi-slice spiral computer tomography $(\mathrm{CT})$ and then normalised to body surface area, is the most practical and accurate way to assess liver reserve function and predict postoperative hepatic insufficiency [7]. While one study 
reported that $\mathrm{SRLV}<250 \mathrm{~mL} / \mathrm{m}^{2}$ is associated with significantly higher risk of hepatic insufficiency than higher SRLV [8], other studies have reported different thresholds [7]. Therefore there is no consensus on an SRLV threshold for postoperative hepatic insufficiency. Determining such a threshold may contribute to patient safety, especially in right hemi-hepatectomy, since the right half of the liver accounts for about $60-75 \%$ of the total liver volume [9], meaning greater risk that tissue removal will leave behind insufficient remnant liver.

The present study aimed to determine threshold SRLVs for HCC patients undergoing right hemi-hepatectomy. Since HCC patients undergoing hepatectomy in China often present with hepatic fibrosis or cirrhosis [10], we wanted to determine threshold SRLVs for these patient subgroups as well, since both conditions can strongly affect preoperative liver function and regeneration of postoperative remnant liver.

\section{Methods}

\section{Ethics statement}

This study was conducted in accordance with the Declaration of Helsinki and was approved by the Ethics Committee of Guangxi Medical University Cancer Hospital (approval LW2019052). All participants provided written informed consent for the use of their clinical records.

\section{Patient enrollment}

This report is an interim analysis of an on-going prospective study involving patients who were scheduled for right hemi-hepatectomy in the Department of Hepatobiliary Surgery at the Affiliated Cancer Hospital of Guangxi Medical University. Eighty-five HCC patients were consecutively enrolled from March 2014 to February 2017. Patients matching the following criteria were enrolled: (1) right-half liver resection; (2) single or multiple tumours confined to the right hepatic lobe, which was confirmed as HCC based on postoperative pathology; (3) all liver tomography and enhancement tests were performed within one week before hepatectomy; and (4) complete pre-, intra- and postoperative clinical data.

Patients were excluded from the study if they (1) had preoperative biliary obstruction or hepatic portal cholangiocarcinoma; (2) had another malignancy such as bile duct cell carcinoma or metastatic carcinoma; (3) received preoperative cancer treatment such as radio- or chemotherapy or transcatheter arterial chemotherapy; (4) previously underwent hepatectomy; or (5) had diabetes, human immunodeficiency virus infection, or other severe diseases.

\section{Clinical and laboratory examinations}

All baseline data, including on demographics, were collected from all patients before hepatic resection. All patients were examined using an 128-slice spiral CT (General Electric, Boston, MA, USA) at 1 week before and 1 week after liver resection. The following tests were also performed in each patient: standard liver and renal function (total bilirubin, albumin, aspartate aminotransferase, alanine transaminase), coagulation function (prothrombin time $[\mathrm{PT}]$ ), haematological examination (white blood cells, red blood cells, platelets, haemoglobin levels), hepatitis $B$ virus screening (HBsAg, HBsAb, HBeAg, HBeAb, HBcAb), and assay of the tumour marker alpha-foetoprotein (AFP).

\section{Three-dimensional liver reconstruction}

Preoperative hepatectomy simulation was performed by two experienced radiologists. Original thin-slice (5 $\mathrm{mm}) \mathrm{CT}$ scans, including the contiguous artery phase, portal venous phase, and delayed phase, were imported into a three-dimensional surgical simulation operation system (Myrian XP Liver 1.30.79.4, Intrasense, Montpellier, France). Portal venous phase images were used for image analysis. Different colors were assigned to different tissues, including liver, tumour, hepatic vein, and portal vein (Fig. 1a-c). Three-dimensional reconstruction was performed using an automated algorithm based on the outline of the tissue. Simulated volumes of liver, tumour, and blood vessels were also calculated.

\section{Simulated hepatic resection}

Simulated hepatic resection was carried out using the Myrian XP Liver system on a surgical plane generated by a $3 \mathrm{D}$ model in the middle hepatic vein region. Adjustments were carried out according to 2D images. Resected liver volume and remnant liver volume were calculated by the system (Fig. 2a-b). SRLV was calculated as remnant liver volume divided by body surface area [11].

\section{Postoperative care and diagnosis of hepatic insufficiency}

All patients received the same postoperative care delivered by the same team of surgeons in the intensive care unit during the early postoperative period. Parenteral nutritional support was provided for patients with cirrhosis. Early enteric nutrition was encouraged once bowel activity resumed. Tests of liver and kidney function, coagulation function, and blood cell counts were performed on postoperative days 1, 3, 5, and 7. Postoperative hepatic insufficiency was diagnosed according to 

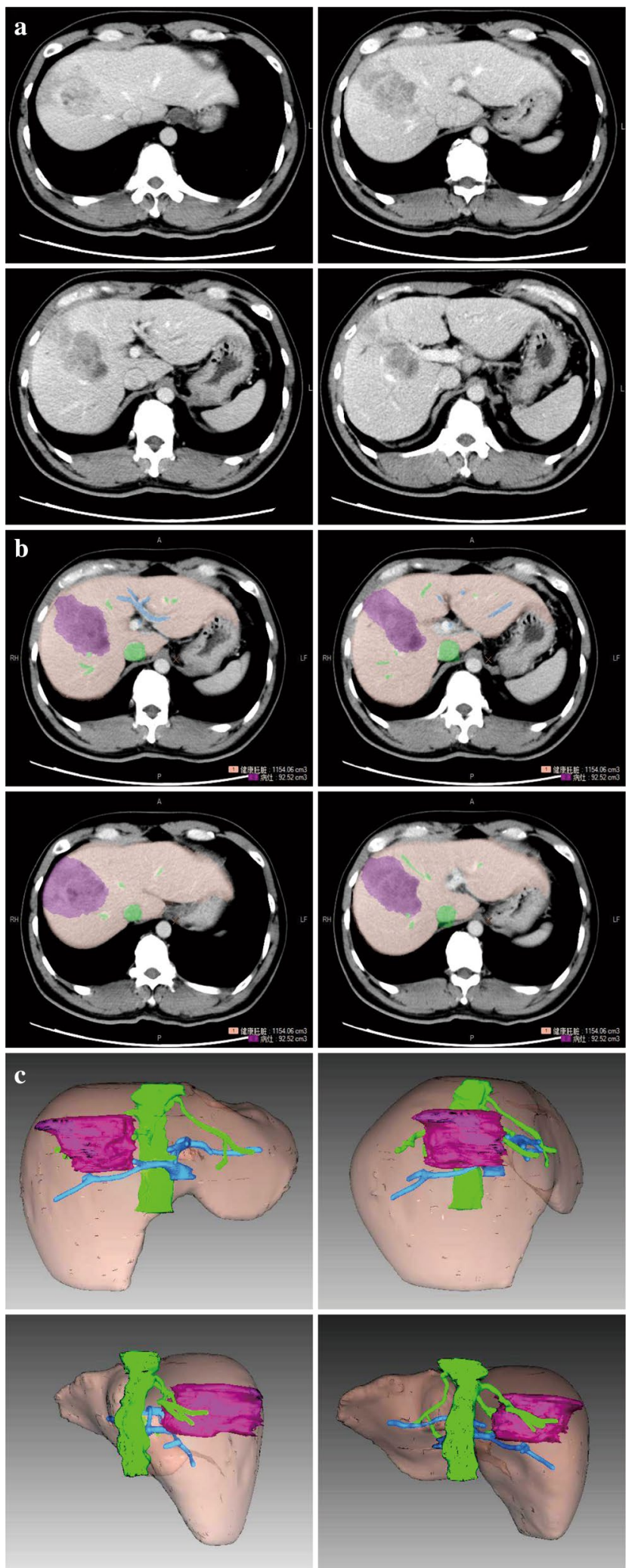

Fig. 1 Representative micrographs showing a portal venous phase; b contours of liver, tumour, hepatic vein and portal vein depicted with different colours; and c 3D reconstruction of liver, tumour, hepatic vein and portal vein 

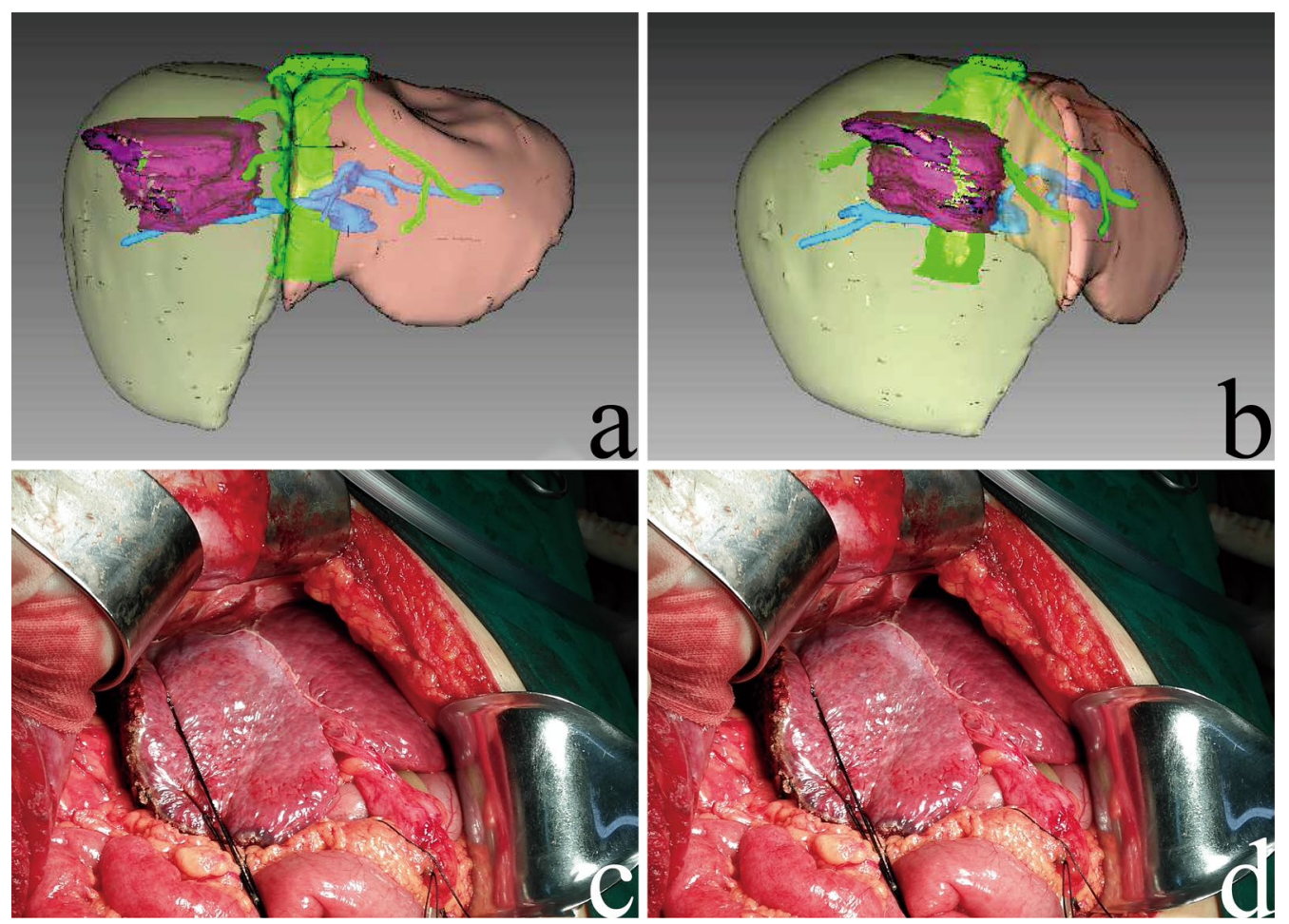

Fig. 2 a, b Representative images of 3D simulations of right hemi-hepatectomy. c, $\mathbf{d}$ Intraoperative photographs showing right hemi-hepatectomy in HCC patients. Yellow area, liver volume removed; purple area, tumour volume; brown area, remnant liver volume

the criteria of the International Study Group of Liver Surgery (ISGLS) [12].

\section{Histological assessment}

Liver tissue samples were fixed in $10 \%$ buffered formalin, embedded in paraffin, and stained with haematoxylin and eosin (HE), Masson's trichrome and reticular fiber. The assessment of hepatic fibrosis was performed according to the analysis of at least $1.5 \mathrm{~cm}$ of liver tissue containing at least five portal tracts. Two histologists independently confirmed the extent of hepatic fibrosis in each sample using the METAVIR scoring system [13]: F0, no fibrosis; F1, expansion of portal zones; F2, expansion of most portal zones and occasional bridging; F3, expansion of most portal zones and marked bridging and occasional modules; or F4, cirrhosis. The absence of clinically significant hepatic fibrosis was defined as hepatic fibrosis stages F0 or F1, while severe hepatic fibrosis was classified as F2 or F3, and cirrhosis as F4 (Fig. 3). Histologists were blinded to clinical data. Disagreements between histologists were resolved by discussion.

\section{Statistical analysis}

Data from continuous variables were expressed as mean \pm standard deviation, and differences in these variables were assessed for significance using Student's $t$ test, while differences in categorical variables were assessed using the chi-squared test. Independent risk factors for hepatic insufficiency were identified using logistic regression. Receiver operating characteristic (ROC) curves were plotted in order to determine threshold SRLVs for predicting hepatic insufficiency. Data analyses were performed using MedCalc analysis software 15.2.0 (Ostend, Belgium). All tests were 2-sided. Differences were considered significant when $\mathrm{p}^{<} 0.05$.

\section{Results}

\section{Demographic and clinical characteristics of 85 HCC} patients

A total of 85 patients were enrolled, including 70 (82.35\%) men and 15 (17.65\%) women (Table 1), and 56 of the 85 patients $(65.88 \%)$ were HBsAg-positive. Sixtyfive patients $(76.47 \%)$ had a single tumour in the right half of the liver, while the remaining $20(23.53 \%)$ had multiple tumours in the right half.

\section{Risk factors for hepatic insufficiency}

Among 85 HCC patients who underwent right hemihepatectomy, 30 (35.29\%) developed postoperative hepatic insufficiency. Despite this, no patients died 

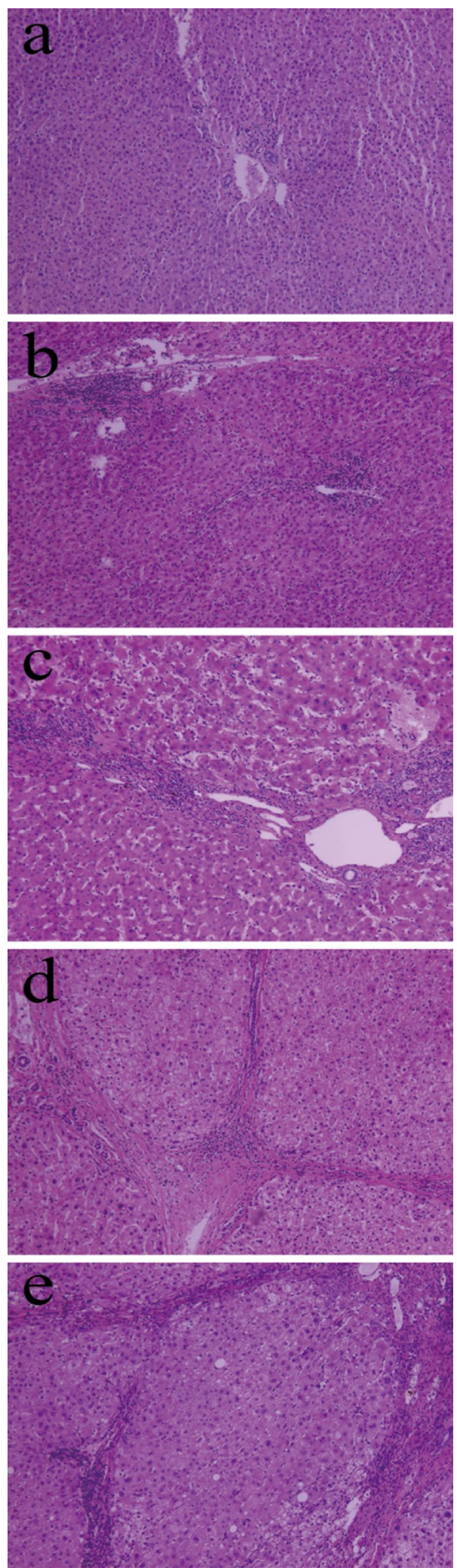

Fig. 3 Representative micrographs showing postoperative pathological hepatic fibrosis staging in liver tissues after haematoxylin and eosin staining. Magnification, 40x. Examples illustrate fibrosis stages a F0, b F1, c F2, d F3, and e F4
Table 1 Demographic and clinical characteristics of 85 Chinese HCC patients who underwent right hemihepatectomy

\begin{tabular}{|c|c|}
\hline Parameter & Value \\
\hline \multicolumn{2}{|l|}{ Sex } \\
\hline Male & $70(82.35)$ \\
\hline Female & $15(17.65)$ \\
\hline \multicolumn{2}{|l|}{ Hepatitis B } \\
\hline Positive & $56(65.88)$ \\
\hline Negative & $29(34.12)$ \\
\hline \multicolumn{2}{|l|}{ Tumour number } \\
\hline Single & $65(76.47)$ \\
\hline Multiple & $20(23.53)$ \\
\hline \multicolumn{2}{|l|}{ Preoperative parameters } \\
\hline Age (year) & $44.71 \pm 11.52$ \\
\hline Platelet count $\left(10^{9} / \mathrm{L}\right)$ & $261.43 \pm 85.68$ \\
\hline Total bilirubin $(\mu \mathrm{mol} / \mathrm{l})$ & $15.51 \pm 11.87$ \\
\hline Albumin (g/L) & $39.05 \pm 4.50$ \\
\hline $\operatorname{ALT}(I U / L)$ & $45.53 \pm 26.09$ \\
\hline AST (IU/L) & $78.16 \pm 62.08$ \\
\hline Prothrombin time (s) & $12.86 \pm 1.21$ \\
\hline Alpha-foetoprotein $(\mu \mathrm{g} / \mathrm{ml})$ & $770.57 \pm 1060.93$ \\
\hline Body surface area $\left(\mathrm{m}^{2}\right)$ & $1.95 \pm 0.16$ \\
\hline Tumour size (cm) & $11.37 \pm 3.69$ \\
\hline Remnant liver volume (ml) & $552.18 \pm 214.32$ \\
\hline $\operatorname{SRLV}\left(\mathrm{ml} / \mathrm{m}^{2}\right)$ & $282.00 \pm 96.20$ \\
\hline \multicolumn{2}{|l|}{ Child-Pugh classification } \\
\hline$A$ & $71(83.53)$ \\
\hline B & $14(16.47)$ \\
\hline \multicolumn{2}{|l|}{ Intraoperative parameters } \\
\hline Blood loss (ml) & $716.67 \pm 650.96$ \\
\hline \multicolumn{2}{|l|}{ Postoperative parameters } \\
\hline \multicolumn{2}{|l|}{ Tumour capsule } \\
\hline Yes & $75(88.24)$ \\
\hline No & $10(11.76)$ \\
\hline \multicolumn{2}{|l|}{ Macrovascular invasion } \\
\hline Yes & $64(75.29)$ \\
\hline No & $21(24.71)$ \\
\hline \multicolumn{2}{|l|}{ Hepatic fibrosis stage } \\
\hline No significant fibrosis & $31(36.47)$ \\
\hline Severe fibrosis & $24(28.24)$ \\
\hline Cirrhosis & $30(35.29)$ \\
\hline Hospital stay (days) & $25.87 \pm 6.56$ \\
\hline
\end{tabular}

Values are $\mathrm{n}(\%)$ or mean $\pm \mathrm{SD}$

$A L P$ alkaline phosphatase, $A L T$ alanine transaminase, $A S T$ aspartate aminotransferase, SRLV standard remnant liver volume

during the perioperative period, defined as from one week before surgery until one week after surgery. Three patients died in-hospital: one died of abdominal hemorrhage at two weeks after surgery, and two died of 
multiple organ failure at four weeks after surgery. All patients were transferred immediately to the intensive care unit for 1-2 days of short-term resuscitation. The following clinicodemographic variables differed significantly in frequency between patients who experienced insufficiency and those who did not (Table 2): height of the patient, PT, remnant liver volume, SRLV and hepatic fibrosis stage.

Binary logistic regression was performed to identify relationships of sex, height, PT, remnant liver volume, SRLV, or hepatic fibrosis stage with postoperative hepatic insufficiency using forward stepwise regression.

Table 2 Comparison of clinicopathologic characteristics between HCC patients who experienced hepatic insufficiency or not after right hemi-hepatectomy

\begin{tabular}{|c|c|c|c|c|}
\hline Characteristic & Insufficiency $(n=30)$ & No insufficiency $(n=55)$ & $\mathrm{X}^{2}(\mathrm{t}$ test) & $P$ \\
\hline \multicolumn{5}{|l|}{ Sex } \\
\hline Male & 28 & 42 & 3.846 & 0.05 \\
\hline Female & 2 & 13 & & \\
\hline \multicolumn{5}{|l|}{$\mathrm{HBsAg}$} \\
\hline Positive & 20 & 36 & 0.013 & 0.91 \\
\hline Negative & 10 & 19 & & \\
\hline \multicolumn{5}{|l|}{ Tumour number } \\
\hline Single & 18 & 34 & 0.027 & 0.869 \\
\hline Multiple & 12 & 21 & & \\
\hline \multicolumn{5}{|l|}{ Preoperative parameter } \\
\hline Age (year) & $43.47 \pm 9.09$ & $45.38 \pm 12.67$ & 0.731 & 0.467 \\
\hline Platelet count $\left(10^{9} / \mathrm{L}\right)$ & $243.08 \pm 95.26$ & $271.44 \pm 79.10$ & 1.390 & 0.171 \\
\hline Total bilirubin $(\mu \mathrm{mol} / \mathrm{l})$ & $16.51 \pm 6.88$ & $14.97 \pm 13.89$ & -0.686 & 0.495 \\
\hline Albumin $(\mathrm{g} / \mathrm{L})$ & $39.62 \pm 4.93$ & $38.74 \pm 4.26$ & -0.824 & 0.414 \\
\hline ALT (IU/L) & $49.27 \pm 24.15$ & $43.49 \pm 27.08$ & -1.009 & 0.317 \\
\hline AST (IU/L) & $94.43 \pm 84.22$ & $69.29 \pm 44.26$ & -1.808 & 0.074 \\
\hline Prothrombin time (s) & $13.33 \pm 1.25$ & $12.61 \pm 1.11$ & -2.612 & $0.012^{*}$ \\
\hline Alpha-foetoprotein $(\mu \mathrm{g} / \mathrm{ml})$ & $821.73 \pm 516.56$ & $742.67 \pm 1267.02$ & -0.405 & 0.686 \\
\hline Body surface area $\left(\mathrm{m}^{2}\right)$ & $1.99 \pm 0.15$ & $1.93 \pm 0.17$ & -1.465 & 0.148 \\
\hline Tumour size (cm) & $12.10 \pm 2.79$ & $10.98 \pm 4.06$ & -1.499 & 0.138 \\
\hline Remnant liver volume (ml) & $489.89 \pm 177.39$ & $586.16 \pm 226.31$ & 2.164 & $0.034^{*}$ \\
\hline $\operatorname{SRLV}\left(\mathrm{ml} / \mathrm{m}^{2}\right)$ & $238.25 \pm 62.14$ & $305.85 \pm 103.35$ & 3.762 & $0.000^{* *}$ \\
\hline \multicolumn{5}{|l|}{ Child-Pugh classification } \\
\hline A & 22 & 49 & 2.452 & 0.117 \\
\hline B & 8 & 6 & & \\
\hline \multicolumn{5}{|l|}{ Intraoperative parameter } \\
\hline Blood loss (ml) & $753.33 \pm 623.52$ & $687.27 \pm 667.72$ & -0.455 & 0.651 \\
\hline \multicolumn{5}{|l|}{ Postoperative parameter } \\
\hline \multicolumn{5}{|l|}{ Tumour capsule } \\
\hline Yes & 25 & 49 & 0.174 & 0.676 \\
\hline No & 5 & 6 & & \\
\hline \multicolumn{5}{|l|}{ Macrovascular invasion } \\
\hline Yes & 26 & 39 & 2.679 & 0.102 \\
\hline No & 4 & 16 & & \\
\hline Hepatic fibrosis stage & & & 6.863 & $0.032^{*}$ \\
\hline No significant fibrosis & 7 & 24 & & \\
\hline Severe fibrosis & 7 & 17 & & \\
\hline Cirrhosis & 16 & 14 & & \\
\hline Hospital stay (days) & $27.37 \pm 7.78$ & $25.51 \pm 5.39$ & -1.785 & 0.069 \\
\hline
\end{tabular}

Values are $\mathrm{n}(\%)$ or mean $\pm \mathrm{SD}$, unless otherwise noted, ${ }^{*} \mathrm{p}<0.05,{ }^{* *} \mathrm{p}<0.01$

$H B s A g$ hepatitis B surface antigen, ALT alanine transaminase, AST aspartate aminotransferase, BSA body surface area, SRLV standard remnant liver volume 
The significance threshold for inclusion in the model was 0.05 , and the threshold for removal was 0.1 . This analysis identified SRLV and hepatic fibrosis stage (both $\mathrm{p}<0.001$ ) as independent risk factors for postoperative hepatic insufficiency after right hemi-hepatectomy for HCC (Table 3).

\section{SRLV thresholds for hepatic insufficiency in HCC patients depending on hepatic fibrosis stage}

ROC analysis showed SRLV to have high sensitivity and specificity for predicting postoperative hepatic insufficiency in HCC patients. The SRLV threshold was $203.2 \mathrm{ml} / \mathrm{m}^{2}$ across all patients, which gave an area under the ROC curve (AUC) of 0.778 , sensitivity of $66.67 \%$, and specificity of $83.64 \%$, $(\mathrm{p}<0.0001$, Fig. $4 \mathrm{a})$. The SRLV threshold was $193.757 \mathrm{ml} / \mathrm{m}^{2}$ for patients with severe hepatic fibrosis (AUC 0.938, sensitivity 91.30\%, specificity $85.71 \%, \mathrm{p}<0.0001$, Fig. $4 \mathrm{~b}$ ) and $224.265 \mathrm{ml} / \mathrm{m}^{2}$ for patients with cirrhosis (AUC 0.888, sensitivity 100\%, specificity 64.29\%, p<0.0001, Fig. 4c).

Table 3 Binary logistic regression analysis to identify factors related to hepatic insufficiency

\begin{tabular}{llll}
\hline Factor & B & Hazard Ratio (95\% CI) & p \\
\hline Sex (male) & 2.008 & $7.451(0.772-71.933)$ & 0.083 \\
Height & 0.07 & $1.072(0.933-1.232)$ & 0.325 \\
Prothrombin time & 0.382 & $1.465(0.837-2.561)$ & 0.181 \\
Remnant liver volume & 0.006 & $1.006(0.989-1.022)$ & 0.514 \\
SRLV & -0.051 & $0.951(0.914-0.989)$ & $0.011^{*}$ \\
Hepatic fibrosis stage & & & \\
Severe fibrosis & 1.045 & $2.845(0.471-17.174)$ & 0.254 \\
Cirrhosis & 3.962 & $52.588(5.547-498.512)$ & $0.001^{* *}$ \\
\hline
\end{tabular}

$\mathrm{Cl}$ confidence interval, SRLV standard remnant liver volume ${ }^{*} \mathrm{p}<0.05,{ }^{* *} \mathrm{p}<0.01$

\section{Discussion}

Liver resection is one of the main treatments for patients with HCC $[14,15]$, but postoperative hepatic insufficiency remains the leading cause of death in these patients. The International Study Group of Liver Surgery (ISGLS) criteria [12] and the 50-50 criteria [16] are widely used to assess the risk that a given patient will suffer postoperative insufficiency. Also widely used are the remnant liver volume $[17,18]$ and SRLV, which normalises the liver volume to body surface area in order to minimise individual differences. Currently there is no global standard for deciding the minimum remnant liver volume that should be ensured to avoid postoperative hepatic insufficiency. We present here threshold values for different subpopulations of HCC patients with cirrhosis or fibrosis after right hemi-hepatectomy, which tends to remove a larger proportion of total liver volume. Therefore the thresholds here may be more conservative and safer than limits proposed after analysis of left hemi-hepatectomy or a combination of right and left hemi-hepatectomy.

The present study found that SRLV was an independent risk factor for postoperative hepatic insufficiency, which is consistent with previous work showing that standard remnant liver volume and indocyanine green retention rate at 15 min were independent risk factors for postoperative insufficiency [7]. At the same time, our threshold SRLV of $203.2 \mathrm{ml} / \mathrm{m}^{2}$ is slightly lower than the threshold of $250 \mathrm{ml} / \mathrm{m}^{2}$ in a study of Japanese patients [8]. This difference may reflect the fact that we examined only patients who underwent right hemi-hepatectomy, while the other study aggregated patients who underwent the right or left procedure. Some studies have suggested that residual hepatocytes in right hemi-hepatectomy may release more cytokines
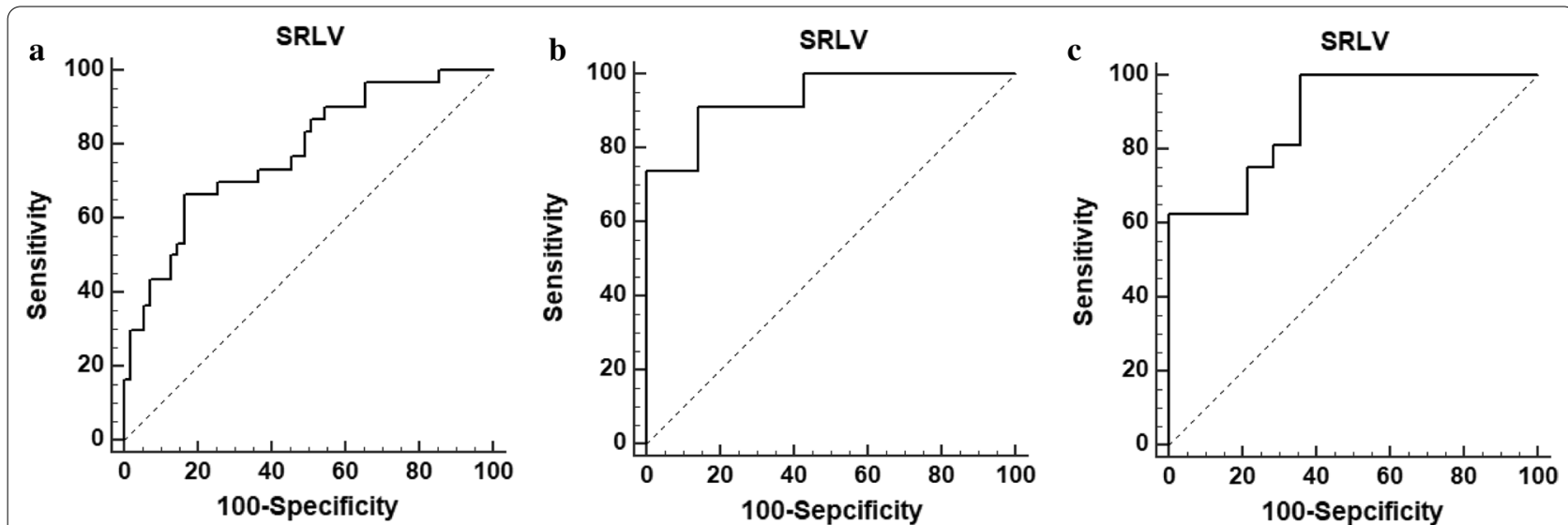

Fig. 4 Receiver operating characteristic curve analysis of the ability of SRLV to predict postoperative insufficiency in a all HCC patients who underwent right hemi-hepatectomy, $\mathbf{b}$ the subgroup of patients with severe hepatic fibrosis, or $\mathbf{c}$ the subgroup of patients with cirrhosis 
than after the left procedure, which may facilitate liver regeneration [19-21]. The lower SRLV in our study may also reflect that only $66 \%$ of patients were positive for hepatitis B virus and only $35 \%$ had cirrhosis, both of which inhibit liver regeneration.

The threshold SRLV was higher in HCC patients with cirrhosis than in those with severe hepatic fibrosis. This may reflect the lower regenerative ability of residual liver tissue in patients with cirrhosis [22, 23]. In this study, we found that hepatic insufficiency is closely related to the severity of hepatic fibrosis, highlighting the need for noninvasive, preoperative techniques to assess the severity of hepatic fibrosis. One promising approach is PSR, which we have validated in HCC patients from the same area of China as in the present study [24].

The results from the present work should be interpreted with caution given that it involved only 30 patients who developed hepatic insufficiency after surgery, including 7 with severe hepatic fibrosis and 16 with cirrhosis. Therefore, our results should be validated and extended in larger studies, preferably ones that also analyse postoperative complications and grade of liver failure. It would also be interesting to validate our SRLV thresholds against baseline liver function based on active contrast uptake in preoperative hepatobiliary magnetic resonance imaging. Future work should analyse not only the absolute volume of the right half of the liver but also the proportion of the right half to the entire liver volume.

\section{Conclusions}

Despite these limitations, the results of this small study suggest that SRLV and hepatic fibrosis stage are independent risk factors for postoperative hepatic insufficiency in HCC patients undergoing right hemihepatectomy. Our results also propose threshold SRLV values that, if validated in larger cohorts, may help guide HCC patient management.

\section{Abbreviations \\ SRLV: Standard remnant liver volume; HCC: Hepatocellular carcinoma; CT: Computer tomography.}

\section{Acknowledgements}

Not applicable.

\section{Authors' contributions}

$L L$ and $J$ designed the study. ZZ and GO performed the experiments. PW, YR, YL, YZ, and JC analysed data. ZZ and PW drafted the manuscript. All authors read and approved the final version of the manuscript.

\section{Funding}

This study was supported by the Suitable Medical and Health Technology Research in Developmental Projects of Guangxi (\$201516), and a Project of the Guangxi Province Education Commission of the Teacher Foundation for Youth (KY2016YB085). The funding bodies played no role in the design of this study, nor in the collection, analysis, or interpretation of the data.
Availability of data and materials

All data generated or analysed during this study are included in this published article.

\section{Ethics approval and consent to participate}

This study was conducted in accordance with the Declaration of Helsinki and was approved by the Ethics Committee of Guangxi Medical University Cancer Hospital (approval LW2019052). Written informed consent was obtained from a legally authorised representative(s) for anonymised patient information to be published in this article.

\section{Consent for publication}

Not applicable.

\section{Competing interests}

The authors state that there are no conflicts of interest to disclose.

\section{Author details}

${ }^{1}$ Department of Hepatobiliary Surgery, Guangxi Medical University Cancer Hospital, No. 71 Hedi Road, Nanning 530021, Guangxi Zhuang Autonomous Region, China. ${ }^{2}$ Department of Radiology, Guangxi Medical University Cancer Hospital, Nanning 530021, Guangxi Zhuang Autonomous Region, China.

3 Department of Pathology, Guangxi Medical University Cancer Hospital, Nanning 530021, Guangxi Zhuang Autonomous Region, China. ${ }^{4}$ Department of Chemotherapy, Guangxi Medical University Cancer Hospital, Nanning 530021, Guangxi Zhuang Autonomous Region, China.

Received: 9 August 2020 Accepted: 14 January 2021

Published online: 23 January 2021

\section{References}

1. Yim HJ, Suh SJ, Um SH. Current management of hepatocellular carcinoma: an Eastern perspective. World J Gastroenterol. 2015;21(13):3826-42.

2. Grandhi MS, Kim AK, Ronnekleiv-Kelly SM, Kamel IR, Ghasebeh MA, Pawlik TM. Hepatocellular carcinoma: from diagnosis to treatment. Surg Oncol. 2016;25(2):74-85.

3. Kantor O, Baker MS. Hepatocellular carcinoma: surgical management and evolving therapies. Cancer Treat Res. 2016;168:165-83.

4. Glantzounis GK, Tokidis E, Basourakos SP, Ntzani EE, Lianos GD, Pentheroudakis $\mathrm{G}$. The role of portal vein embolization in the surgical management of primary hepatobiliary cancers. A systematic review. Eur J Surg. 2017:43(1):32-41.

5. Sparrelid E, Jonas E, Tzortzakakis A, Dahlén U, Murquist G, Brismar T, et al. Dynamic evaluation of liver volume and function in associating liver partition and portal vein ligation for staged hepatectomy. J Gastrointest Surg. 2017;21(6):967-74.

6. Ribero D, Zimmitti G, Aloia TA, Shindoh J, Fabio F, Amisano M, et al. Preoperative cholangitis and future liver remnant volume determine the risk of liver failure in patients undergoing resection for hilar cholangiocarcinoma. J Am Coll Surg. 2016;223(1):87-97.

7. Du ZG, Li B, Feng X, Yin J, Yan LN, Wen TF, et al. Combined indocyanine green test and standard remnant liver volume to predict posthepatectomy hepatic insufficiency for the patients with hepatocellular carcinoma. Zhonghua Wai Ke Za Zhi. 2010;48(3):189-92.

8. Shirabe K, Shimada M, Gion T, Hasegawa H, Takenaka K, Utsunomiya T, et al. Postoperative liver failure after major hepatic resection for hepatocellular carcinoma in the modern era with special reference to remnant liver volume. J Am Coll Surg. 1999;188(3):304-9.

9. Pickhardt PJ, Malecki K, Hunt OF, Beaumont C, Kloke J, Ziemlewicz TJ, et al. Hepatosplenic volumetric assessment at MDCT for staging liver fibrosis. Eur Radiol. 2017;27(7):3060-8.

10. Lei Z, Li J, Wu D, Xia Y, Wang Q, Si A, et al. Nomogram for preoperative estimation of microvascular invasion risk in hepatitis B virus-related hepatocellular carcinoma within the Milan criteria. JAMA Surg. 2016:151(4):356-63.

11. Li J, Lei B, Nie X, Lin L, Tahir SA, Shi W, et al. A comprehensive method for predicting fatal liver failure of patients with liver cancer resection. Medicine. 2015;94(17):e784. 
12. Rahbari NN, Garden OJ, Padbury R, Brooke-Smith M, Crawford M, Adam $R$, et al. Posthepatectomy liver failure: a definition and grading by the International Study Group of Liver Surgery (ISGLS). Surgery. 2011;149(5):713-24.

13. Li Q, Lu C, Li W, Huang Y, Chen L. The gamma-glutamyl transpeptidase to platelet ratio for non-invasive assessment of liver fibrosis in patients with chronic hepatitis B and non-alcoholic fatty liver disease. Oncotarget. 2017;8(17):28641-9.

14. Akoad ME, Pomfret EA. Surgical resection and liver transplantation for hepatocellular carcinoma. Clin Liver Dis. 2015;19(2):381-99.

15. Colombo M, Sangiovanni A. Treatment of hepatocellular carcinoma: beyond international guidelines. Liver Int. 2015;35(Suppl 1):129-38.

16. Balzan S, Belghiti J, Farges O, Ogata S, Sauvanet A, Delefosse D, et al. The "50-50 criteria" on postoperative day 5: an accurate predictor of liver failure and death after hepatectomy. Ann Surg. 2005;242(6):824-8, discussion 8-9.

17. Cho A, Chung YE, Choi JS, Kim KS, Choi GH, Park YN, et al. Feasibility of preoperative FDG PET/CT total hepatic glycolysis in the remnant liver for the prediction of postoperative liver function. AJR Am J Roentgenol. 2017;208(3):624-31

18. Shi ZR, Yan LN, Du CY. Donor safety and remnant liver volume in living donor liver transplantation. World J Gastroenterol. 2012;18(48):7327-32.

19. Maldonado G, Greenland S. Simulation study of confounder-selection strategies. Am J Epidemiol. 1993;138(11):923-36.
20. Myronovych A, Murata S, Chiba M, Matsuo R, Ikeda O, Watanabe M, et al Role of platelets on liver regeneration after $90 \%$ hepatectomy in mice. J Hepatol. 2008;49(3):363-72.

21. Gruttadauria S, Parikh V, Pagano D, Tuzzolino F, Cintorino D, Miraglia R, et al. Early regeneration of the remnant liver volume after right hepatectomy for living donation: a multiple regression analysis. Liver Transpl. 2012;18(8):907-13.

22. Dorn C, Heilmann J, Hellerbrand C. Protective effect of xanthohumol on toxin-induced liver inflammation and fibrosis. Int J Clin Exp Pathol. 2012;5(1):29-36.

23. Chan CC, Cheng LY, Lin CL, Huang YH, Lin HC, Lee FY. The protective role of natural phytoalexin resveratrol on inflammation, fibrosis and regeneration in cholestatic liver injury. Mol Nutr Food Res. 2011;55(12):1841-9.

24. Ouyang GX, Zhang YM, Zhu SL, Wang P, Ren Y, Li JH, et al. A novel, non-invasive model for diagnosing liver fibrosis stage in patients with hepatocellular carcinoma. Sci Rep. 2018;8(1):13074.

\section{Publisher's Note}

Springer Nature remains neutral with regard to jurisdictional claims in published maps and institutional affiliations.
Ready to submit your research? Choose BMC and benefit from:

- fast, convenient online submission

- thorough peer review by experienced researchers in your field

- rapid publication on acceptance

- support for research data, including large and complex data types

- gold Open Access which fosters wider collaboration and increased citations

- maximum visibility for your research: over 100M website views per year

At BMC, research is always in progress.

Learn more biomedcentral.com/submissions 